\title{
Pemberdayaan Masyarakat Melalui Penyuluhan Pengolahan Buah Mangrove Sebagai Sumber Pendapatan Alternatif Masyarakat Pesisir Karawang
}

\author{
Kuswarini Sulandjari ${ }^{1}$, Abubakar $^{2}$, Dessy Agustina Sari ${ }^{3)}$ \\ 1) dan 2). Program Study Agribisnis, Fakultas Pertanian Unsika Jln. HS. Ronggo Waluyo Teluk \\ Jambe Timur Karawang. \\ 3). Program Study Teknik Kimia, Fakultas Teknik Unsika Jln. HS. Ronggo Waluyo Teluk \\ Jambe Timur Karawang \\ Email : kuswarini.sulandjari@staff.unsika.ic.id
}

Received: 04 March 2021; Revised: 26 April 2021; Accepted: 28 July 2021

DOI: http://dx.doi.org/10.37905/aksara.7.3.1087-1096.2021

\begin{abstract}
Abstrak
Buah mangrove dapat dijadikan olahan yang bermanfaat dan bernilai ekonomi. Potensi tersebut belum dimanfaatkan karena kurangnya pengetahuan dan kemampuan masyarakat. Tujuan pengabdian kepada masyarakat ini : Meningkatkan pengetahuan, keterampilan dan tindakan dalam mengolah buah mangrove sebagai sumber pendapatan alternatif. Menggunakan pendekatan partisipatif, penyuluhan secara perorangan dan kelompok, dengan metode : anjangsoso, ceramah ; (FGD), demosntrasi cara dan demonstrasi hasil. Hasil : penyuluhan jelas, mudah diterima dan sangat berguna; Hasil olahan : sirup, selai, permen, dodol dan sabun buah mangrove; Terdapat peningkatan jumlah sasaran yang mengetahui, manfaat mangrove untuk lingkungan (20\%) dan ekonomi $(70 \%)$ olahan dan cara mengolah buah mangrove menjadi sirup (15\%), selai $(100 \%)$, permen $(95 \%)$, dodol $(25 \%)$ dan sabun $(100 \%)$, yang mau/ingin mengolah dari $60 \%$ menjadi $100 \%$, dan bisa mengolah $(50 \%)$. Sasaran yang belum mencoba mengolah $(15 \%)$, belum ada yang mencoba mengolah menjadi selai, permen dan sabun, karena kurangnya : pemahaman, kemampuan, kepercayaan diri, modal dan fasilitas.
\end{abstract}

Kata kunci : buah mangrove, pengolahan, penyuluhan, pemberdayaan

\begin{abstract}
Mangrove fruit can be processed that is useful and has economic value. This potential has not been exploited due to the lack of community knowledge and capabilities. The purpose of this community service: To increase knowledge, skills and actions in processing mangrove fruit as an alternative source of income. Using a participatory approach, counseling individually and in groups, with the methods: anjangsoso, lectures; (FGD), demonstration of methods and demonstration of results. Results: counseling is clear, easy to accept and very useful; Processed products: syrup, jam, candy, lunkhead and mangrove fruit soap; There is an increasing number of targets who know the benefits of mangroves for the environment (20\%) and the economy (70\%) processed and how to process mangrove fruit into syrup (15\%), jam (100\%), candy (95\%), lunkhead (25\%)) and soap (100\%), who want/want to process from $60 \%$ to $100 \%$, and can process $(50 \%)$. The target who has not tried processing (15\%), has not tried to process it into jam, candy and soap, due to lack of understanding, ability, self-confidence, capital and facilities.
\end{abstract}

Keywords : mangrove fruit, processing, counseling, empowerment 


\section{PENDAHULUAN}

Undang-Undang Desa tahun 2014 membawa prinsip-prinsip pembangunan berbasis pemberdayaan masyarakat di Indonesia. Pemberdayaan adalah suatu proses dan upaya untuk memperoleh atau memberikan daya, kekuatan atau kemampuan kepada individu atau masyarakat lemah agar dapat mengeidentifikasi, menganalisis, menetapkan kebutuhan dan potensi serta masalah yang dihadapi dan sekaligus memilih alternatif pemecahannya dengan mengoptimalkan sumberdaya dan potensi yang dimiliki secara mandiri (Stewart, Allen Mikcchell, 1994).

Desa Sukakerta merupakan salah satu desa di Kabupaten Karawang yang terletak di pesisir pantai utara pulau Jawa. Salah satu ekosistem yang sangat penting adalah ekosistem mangrove. Keberadaan hutan mangrove penting secara ekologis, karena pendukung rantai pangan di sekitarnya melindungi pantai dari angin kencang, abrasi dan tsunami (Griffin dan Ebert, 1996). Disamping manfaat ekologis, mangrove juga bermanfaat scara ekonomi. Fungsi ekonomis diantaranya sebagai penghasil kayu untuk bahan baku dan bahan bangunan, bahan makanan dan obat-obatan (Lilian Sarah Hiariey, 2009). Bagian tanaman mangrove lainnya adalah buah yang disebut jya : pedada, pidada atau kapidada. Buah mangrove yang rasanya asam, manis mempunyai kekhasan, dapat digunakan dan diolah untuk berbagai produk Buah mangrove bisa dijadikan alternatif olahan pangan yang bermanfaat bagi masyarakat. Buah mangrove bisa diolah menjadi sirup, yang ternyata mampu mengempiskan tumor dalam tubuh. Kemudian sisa olahan sirup dapat dijadikan selai, permen, cincau juga dodol. Selain itu buah mangrove juga dapat diolah menjadi kecap, sabun, lulur bahkan pewarna batik. Perlu penekanan kepedulian masyarakat terhadap mangrove. Salah satunya, yakni dengan memanfaatkan buah mangrove. Namun nyatanya belum banyak dikenal masayarakat umum. Alhasil banyak orang memperlakukan semena-mena pohon dan buah ini lantaran tak mengetahui kegunaannya. Atas dasar itu, perlu ditemukan cara bagaimana mangrove bisa membantu ekonomi masyarakat tanpa harus ditebang (Lilian Sarah Hiariey, 2009).

Masyarakat di Desa Sukakerta mengenal manfaat buah mangrove, mengkonsumsi dan mengolahnya menjadi beberapa produk. Terdapat satu kelompok usaha bersama (KUB) "Nali Jaya" di bawah kelompok "Kreasi Alam Bahari". KUB Nali Jaya melakukan kegiatan mengolah buah mangrove menjadi dodol dan sirup, serta mencoba menjualnya. Produksi secara sederhana, menggunakan alat apa adanya, dengan teknik pengolahan alakadarnya. Kelompok tersebut berusaha memasarkan, akan tetapi masih bersifat pasif. Akibatnya produk kurang laku, dan tidak habis terjual. Akhirnya tidak berproduksi lagi karena tidak ada modal. Dengan demikian dapat dikatakan bahwa, belum ada pemanfaatan tanaman mangrove seperti buah, daun sebagai produk olahan yang bernilai ekonomi sebagai sumber pendapatan alternatif masyarakat pesisir Kecamatan Cilamaya Wetan Kabupaten Karawang.

Berdasarkan hal tersebut perlu pemberdayaan masyarakat desa Sukakerta berbasis pada potensi wilayah pesisir, termasuk ekosistemnya, melalui pengolahan buah mangrove. Apabila buah mangrove dapat diolah dan dipasarkan maka permintaan buah mangrove akan meningkat. Dengan demikian masyarakat termotivasi untuk mau menanam, memelihara sampai berbuah, sehingga mangrove terselamatkan. Oleh karena itu pengabdian masyarakat ini ditujukan kepada kelompok usaha bersama yang sudah terbentuk (K U B Nali Jaya), diharapkan dapat menghasilkan pendapatan alternatif dari 
olahan buah mangrove dan berkembang ke masyarakat sekitar. Hal ini akan berdampak positif pada upaya konservasi mangrove.

\section{METODE}

Tahapan pengabdian masyarakat ini adalah : analisis situasi, perumusan masalah dan tujuan pengabdian, persiapan, pelaksanaan dan evaluasi, dengan menggunakan pendekatan partisipatip. Masyarakat diberi motivasi agar mempunyai kemauan menanam dan memelihara tanaman mangrove. Untuk memotivasi masyarakat, agar mau menanam mangcove maka perlu disampaikan manfaat mangrove secara ekologis dan ekonomis sebagai alternatif tambahan penghasilan Untuk tambahan penghasilan diperlukan kemampuan dan kemauan memanfaatkan mangrove, diantaranya pengolahan buah mangrove. Penyampaian macam-macam cara pengolahan buah mangrove dilakukan dengan penyuluhan. Penyuluhan merupakan sistem belajar untuk menjadi mau, tahu, dan bisa menyelesaikan masalah yang dihadapi (Mardikanto, 1993). Menurut Kartasapoetra (1994), tujuan penyuluhan jangka pendek, diantaranya menimbulkan dan merubah pengetahuan, kecakapan, sikap dan bentuk tidakan petani.

Penyuluh pada pengabdian masyarakat ini adalah mahasiswa peserta KKN serta dosen pembimbing lapangan. Sasaran pengabdian masyarakat ini adalah pengurus dan anggota Kelompok Usaha Bersama "Nali Jaya". KUB Nali Jaya merupakan kelompok wanita nelayan yang berkegiatan mengolah hasil laut. Kelompok ini berada dalam lingkup Kelompok "Kreasi Alam Bahari". Kegiatan berlangsung dari bulan September sampai dengan November tahun 2020.

Pengabdian masyarakat menggunakan pendekatan partisipatif, dengan penyuluhan secara personal dan kelompok. Metode penyuluhan perorangan, penyuluh berhubungan langsung kepada sasaran secara per orangan, secara kunjungan (anjangsoso) ke rumah dan pertemuan di pantai. Pertemuan dilakukan dengan pengurus KUB dan beberapa anggota. Pada pertemuan ini dilakukan diskusi dan wawancara tentang pemanfaatan mangrove, keinginan sasaran dan permasalahan yang dihadapi. Diskusi kelompok juga dengan metode FGD. Pendekatan kelompok ditujukan kepada sekelompok orang tertentu yang telah diketahui latar belakangnya (Soedarmanto, 1992). Secara kelompok penyuluhan diberikan kepada anggota dan pengurus KUB. Pendekatan kelompok tersebut dengan metode : ceramah, demonstrasi cara dan demostrasi hasil.

Dalam penyuluhan disampaikan pesan-pesan berupa materi penyuluhan. Materi penyuluhan pada pengabdian masyarakat ini diantaranya : 1. Manfaat mangrove bagi lingkungan, ekonomi dan sosial. 2. Mengolahan buah mangrove menjadi sirup, selai, dodol dan sabun. 3. Cara mengolah buah mangrove menjadi sirup, selai, dodol dan sabun. Materi-materi tersebut disampaikan dengan menggunakan metode penyuluhan : anjangsono, ceramah, demonstrasi cara dan demonstrasi hasil. Demostrasi cara dilakukan bersama anggota KUB.

Setelah kegiatan pengabdian, dilakukan evaluasi perubahan perilaku. Evaluasi dilakukan dengan menggunakan metode sensus terhadap 20 orang angota KUB. Data untuk evaluasi tentang perilaku sasaran merupakan data kualitatif dan kualitatif. Pengambilan data dengan cara wawancara menggunakan kuesioner semi terstruktur. Data ditabulasi kemudian dideskripsikan. Evaluasi dilakukan satu bulan setelah pelaksanaan kegiatan pengabdian. 


\section{Hasil dan Pembahasan \\ Karakteristik Anggota KUB Mitra}

Dari 20 orang pengurus dan anggota KUB, 2 orang berusia 15-20 tahun, 3 berusia 20-25 tahun, 4 orang berusia 31-35 tahun, 3 orang berusia 36-40 tahun, 2 orang berusi 41-45, 1 berusia antara 46-50 tahun, 1 orang berusia antara 51-55 tahun, 2 orang berusia antara 55-60 tahun. Pendidikan responden : tidak sekolah 1 orang, yang berpendidikan SD ada 15 orang, sisanya SMP 2 orang dan SMA 2 orang. Pekerjaan (mata pencaharian) responden : 15 orang tidak bekerja, wirausaha 2 orang, pedagang 2 orang dan satu orang masih sekolah SMA.

\section{Pelaksanaan Penyuluhan}

Analisis situasi merupakan tahap awal pengabdian masyarakat. Tahap berikutnya adalah perumusan masalah dan tujuan pengabdian. Dilanjutkan langkah berikutnya adalah persiapan dan pelaksanaan. Pada tahap persiapan dilakukan pembekalan kepada penyuluh dalam hal ini dosen dan mahasiswa peserta KKN. Materi yang disampaikan diantaranya tentang pemberdayaan masyarakat, penyuluhan, tanaman mangrove, fungsi tanaman mangrove, pengolahan buah mangrove. Selain itu juga pengorganisasian biaya, alat, bahan, tempat, sasaran dan. Pengorganisasian biaya, alat, bahan, tempat, sasaran.

Pelaksanaan penyuluhan meliputi : Anjangsoso, FGD, diskusi on line, ceramah, demonstrasi cara, demonstrasi hasil. Ceramah dilaksanakan untuk menyampaikan materi tentang : tanaman mangrove, fungsi tanaman mangrove secara ekologi dan ekonomi sebagai alternatif penghasilan keluarga. Bagian tanaman mangrove yang bermanfaat diantaranya buah mangrove. Materi ini disampaikan agar anggota KUB memahami manfaat mangrove untuk lingkungannya. Hal ini dimaksudkan untuk menimbulkan kemauan melestarikan mangrove dengan mengambil hasilnya untuk penghasilan tambahan. Untuk meningkatkan pengetahuan tentang mangrove dan pengolahan buah mangrove dilakukan penyuluhan dengan menjelaskan secara personal dan ceramah. Pemilihan jenis olahan buah mangrove ditentukan melalui diskusi. Materi yang disampaikan adalah : 1. Manfaat mangrove bagi lingkungan, dan ekonomi; 2. Manfaat ekonomi diantaranya sebagai alternatif tambahan penghasilan keluarga ; 3. Penghasilan dari olahan buah mangrove menjadi sirup, selai, dodol dan sabun ; 4. Resep mengolah buah mangrove menjadi sirup, selai, dodol dan sabu. Penyuluhan dan materi penyuluhan diantaranya tertera pada Gambar 1.
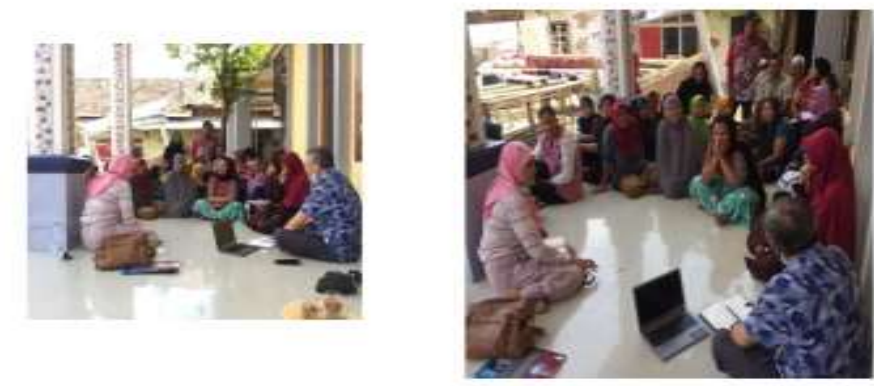

Gambar 1. Ceramah Manfaat Tanaman Mangrove dan Pengolahan Buah Mangrove 

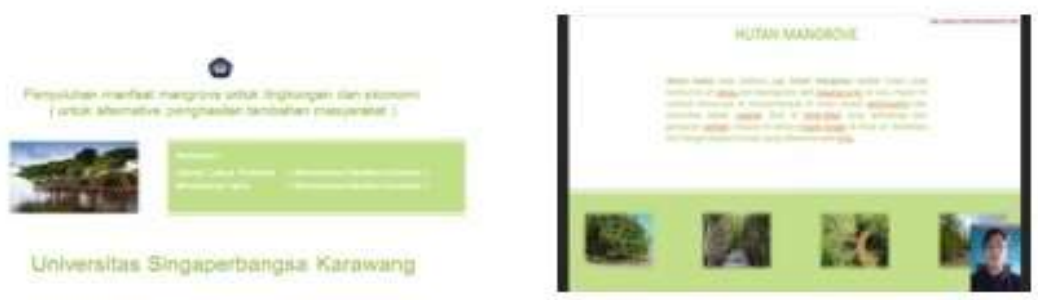

Materi penvuluhan manfaat dan fungsi tanaman mangrove bagi lingkungan dan ekonomi

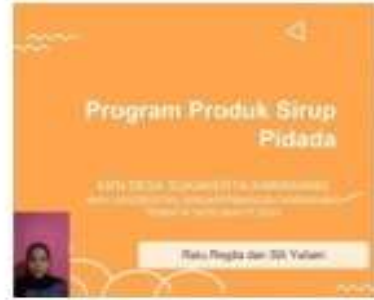

Materi penyuluhan pembuatan sirup dari buah mangrove

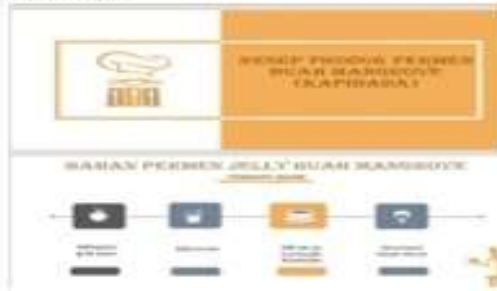

Materi penyuluhan pembuatan permen dari buah mangrov

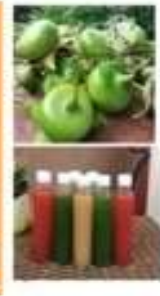

mangrove
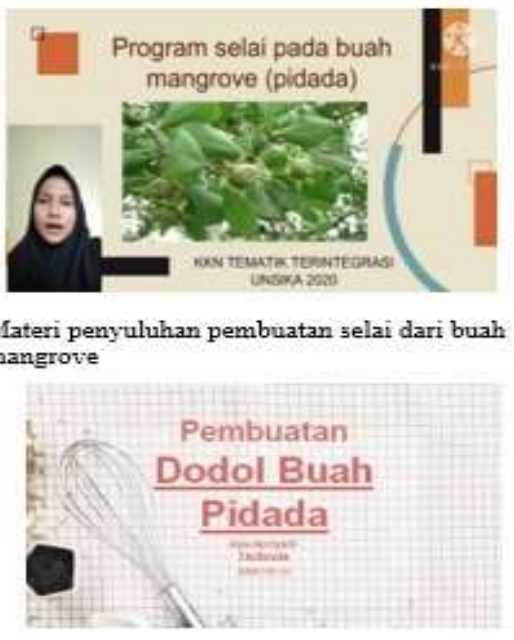

Materi penyuluhan pembuatan dodol dari buah mangrove

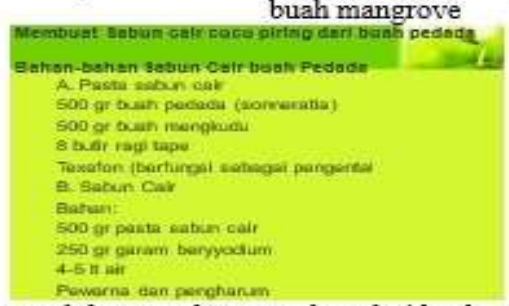

Materi penyuluhan pembuatan sabun dari buah mangrove

Gambar 2. Materi Ceramah Cara Mengolah Buah Mangrove

\section{Demonstrasi cara}

Demonstrasi pengolahan buah mangrove dilaksanakan di kediaman ketua KUB pada hari kamis tanggal 5 November 2020. Demonstrasi cara dilakukan dengan menunjukkan cara membuat sirup, selai, permen, dodol dan sabun. Masing-masing cara mengolah produk ditunjukkan resep dan cara membuatnya secara bertahap (Gambar 2). Peserta diajak ikut serta mengerjakan pengolahan buah, dengan penjelasan dan bimbingan. Tujuan demonstrasi ini adalah mengajarkan keterampilan mengolah buah mangrove menjadi sirup, selai, perme, dodol dan sabun. Selain itu dmaksudkan untuk menumbuhkan kepercayaan pada diri peserta, merangsang kegiatan dan menyebarluaskan cara pengolahan buah mangrove. 

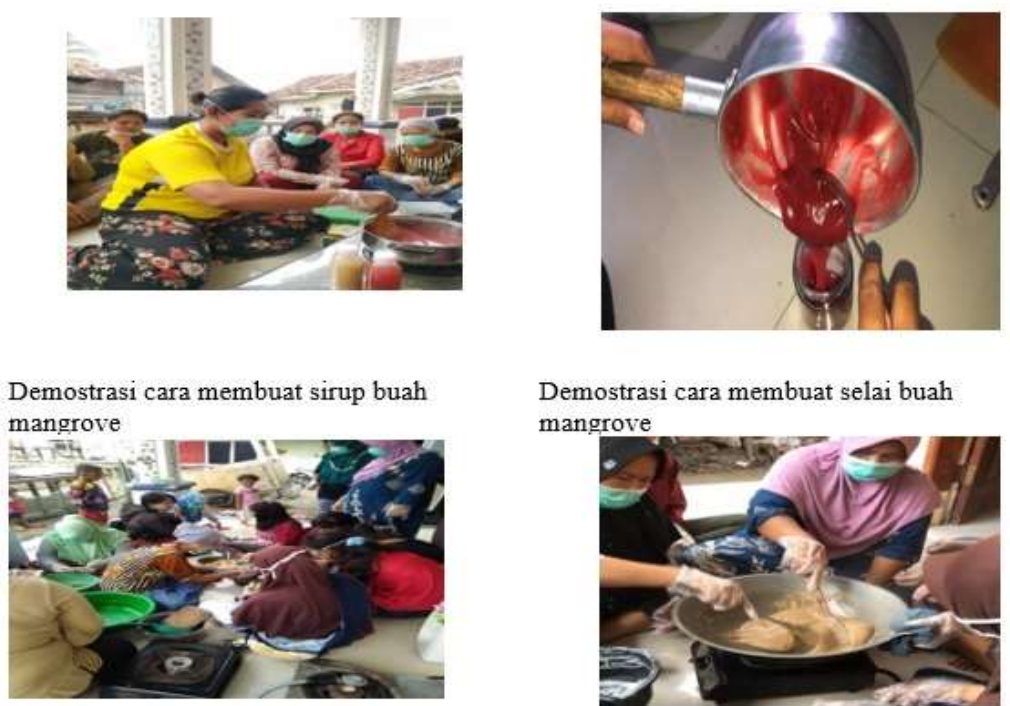

Demostrasi cara membuat permen buah mangrove

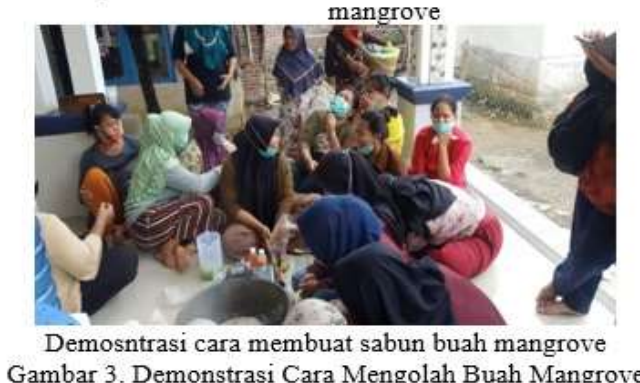

Demostrasi cara membuat selai buah mangrove

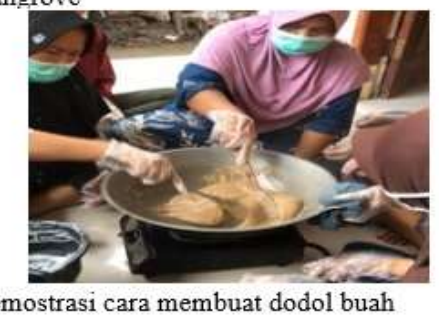

Demostrasi cara membuat dodol buah mangrove

\section{Demonstrasi hasil}

Demonstrasi hasil dilakukan dengan memperlihatkan hasil yang diperoleh dari penerapan cara pengolahan buah mangrove menjadi sirip, selai, permen, dodol dan sabun (Gambar 4). Dijelaskan bahwa untuk pemasaran, hasil olahan masih memerlukan uji produk. Uji produk meliputi rasa dan uji hygiene. Selain itu juga diperlukan analisis kelayakan finansial usaha. Produk juga perlu terus ditingkatkan kualitas dan daya tarik terhadap konsumen dengan melakukan uji coba atau eksperimen. Dalam demostrasi ini peserta dipersilahkan mengamati dan merasakan sirup, selai, permen dan dodol buah mangrove. Anggota KUB diperkenankan juga mencoba menggunakan sabun buah mangrove untuk mencuci piring. Tujuannya memberi pengalaman kepada sasaran tentang hasil olahan buah mangrove agar percaya akan hasil tersebut, sehingga mempercepat sasaran untuk menerapkan pengolahan buah mangrove. 

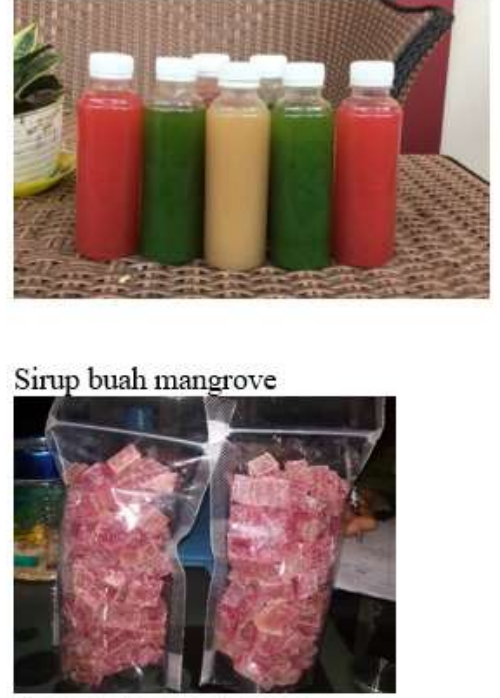

Permen buah mangrove
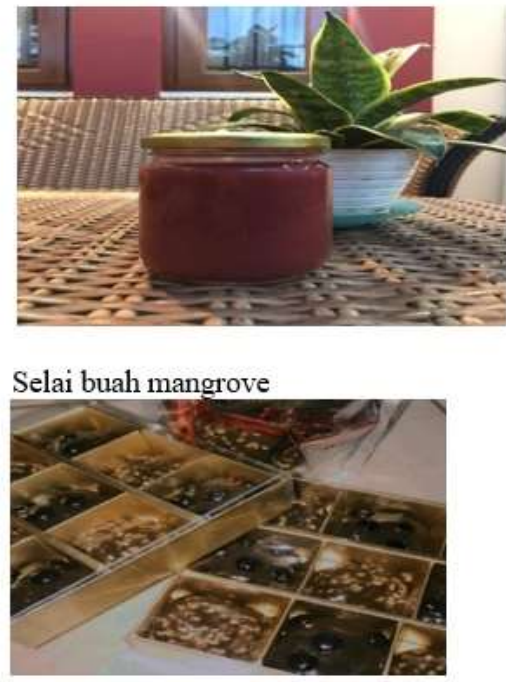

Dodol buah mangrove

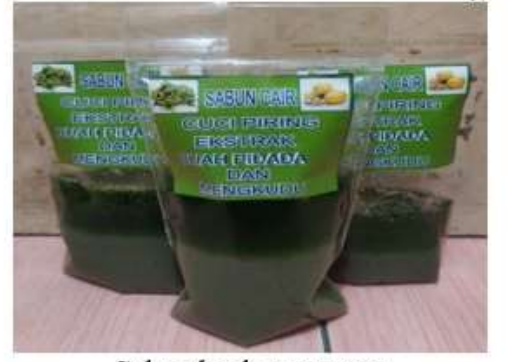

Sabun buah mangrove

Gambar 4. Hasil Olahan Buah Mangrove

\section{Respon Anggota KUB Mitra}

Respon atau tanggapan menurrut Mardikanto (1989) adalah segala sesuatu yang diperbuat oleh seseorang setelah mendapatkan stimulus. Menurut Azwar (1995), respon diklasifikasikan menjadi tiga yaitu : 1. Respon kognitif berisi persepsi, kepercayaan dan stereotipe yang dimiliki individu mengenai sesuatu; 2. Respon afektif merupakan perasaan individu terhadap obyek; 3 . Konatif merupakan respon berupa tindakan dan pernyataan mengenai perilaku dan kecenderungan berperilaku.

Dari hasil wawancara menunjukkan bahwa $50 \%$ responden menyatakan penyuluhan sangat berguna dan $50 \%$ menyatakan berguna. Delapan puluh persen menyatakan penyuluh menyampaikan materi dengan jelas, $10 \%$ sangat jelas, $5 \%$ menyatakan kurang jelas.

\section{Perubahan Pengetahuan}

Menurut Kamus Bahasa Indonesia, pengetahuan adalah sesuatu yang diketahui. Pengetahuan merupakan hasil dari tahu, dan ini terjadi setelah orang melakukan penginderaan terhadap suatu objek tertentu. Penginderaan terjadi melalui pancaindra manusia, yakni indra penglihatan, pendengaran, penciuman, rasa dan raba. Sebagian besar pengetahuan manusia diperoleh melalui mata dan telinga (Notoatmodjo, 2007).

Pengetahuan atau kognitif adalah bagian yang sangat penting dalam membentuk tindakan seseorang (overt behavior) sebelum orang mengadopsi perilaku baru, (Rogers, 
1983), melalui proses berurutan yaitu: a. Kesadaran (Awarness), yaitu seseorang menyadari atau mengetahui stimulus (objek) terlebih dahulu. b. Tertarik (Interest), maksudnya orang mulai tertarik pada stimulus. c. Mempertimbangkan (Evaluation), menimbang-nimbang baik tidaknya stimulus tersebut bagi dirinya. d. Mencoba (Trial), yakni dimana orang mulai mencoba perilaku baru. e. Mengadaptasi (Adaptation), dimana subjek telah berperilaku baru sesuai dengan pengetahuan, kesadaran dan sikapnya terhadap stimulus.

Dari hasil wawancara dengan responden, jumlah responden yang tahu tentang manfaat mangrove dan pengolahan buah mangrove ditunjukkan pada Tabel 1.

Tabel 1. Pengetahuan Responden tentang Manfaat Mangrove dan Pengolahan Buah Mangrove

\begin{tabular}{|c|c|c|c|c|}
\hline \multirow[b]{2}{*}{ Pengetahuan } & \multicolumn{2}{|c|}{ Sebelum Penyuluhan } & \multicolumn{2}{|c|}{ Sesudah Penyuluhan } \\
\hline & Tidak tahu & $\begin{array}{l}\text { Tahu } \\
(\%) \text { res }\end{array}$ & $\begin{array}{l}\text { Tidak tahu } \\
\text { ponden }\end{array}$ & Tahu \\
\hline Manfaat mangrove untuk lingkungan & 25 & 75 & 5 & 95 \\
\hline $\begin{array}{l}\text { Manfaat mangrove untuk alternatif } \\
\text { pendapatan }\end{array}$ & 85 & 15 & 15 & 85 \\
\hline Sirup buah mangrove & 15 & 85 & - & 100 \\
\hline Selai buah mangrove & 100 & - & - & 100 \\
\hline Permen buah mangrove & 95 & 5 & - & 100 \\
\hline Dodol buah mangrove & 75 & 25 & - & 100 \\
\hline Sabun buah mamgrove & 100 & - & - & 100 \\
\hline
\end{tabular}

Dari tabel tersebut dapat dilihat bahwa terjadi peningkatan jumlah responden (20\%) yang mengetahui manfaat mangrove bagi lingkungan dari sebelum penyuluhan (75\%) dibandingkan dengan sesudah penyuluhan (95\%). Peningkatan jumlah responden yang mengetahui manfaat ekonomi tanaman mangrove $(60 \%)$. Terjadi peningkatan jumlah responden yang mengetahui olahan buah mangrove menjadi sirup (15\%), selai $100 \%$ ), permen (95\%), dodol (25\%), sabun (100\%) dari sebelum penyuluhan dibandingkan dengan setelah penyuluhan. Peningkatan paling banyak yaitu olahan sabun (100\%) dan selai (100\%), disusul permen (75\%), dodol (75\%) dan sirup (15\%).

\section{Perubahan Sikap}

Sikap adalah pernyataan evaluatif terhadap objek, orang atau peristiwa. Hal ini mencerminkan perasaan seseorang terhadap sesuatu (Robbisn, 2007). Notoadmodjo (2003) mengemukakan bahwa sikap (attitude) merupakan reaksi atau respon yang masih tertutup dari seseorang terhadap stimulus atau obyek.

Berdasarkan hasil wawancara, dapat dijelaskan tentang sikap responden dalam hal mengolah buah mangrove. Perubahan sikap berupa keinginan untuk mengolah buah mangrove. Sebelum penyuluhan, responden yang tidak ingin mengolah sejumlah $40 \%$, yang ingin mengolah sejumlah $60 \%$. Setelah penyuluhan $100 \%$ ingin mengolah buah mangrove. Alasanya adalah sebagai alternatif penghasilan dan menambah penghasilanan $(70 \%)$, ingin memberi manfaat sumberdaya (25\%), menambah /membuka lapangan kerja $(5 \%)$. 


\section{Perubahan Keterampilan}

Keterampilan menurut Gordon (1994) merupakan sebuah kemampuan seseorang dalam mengoperasikan pekerjaan itu secara lebih mudah serta tepat. Pendapat tentang keterampilan menurut Gordon ini lebih kearah pada aktivitas/kegiatan yang memiliki sifat psikomotorik. Analisis berdasarkan jawaban hasil wawancara tentang pernyataan responden. Responden yang menjawab "bisa mengolah buah mangrove menjadi sirup, selai, permen dan dodol serta sabun" termasuk kategori terampil. dan yang "tidak/belum bisa mengolah buah mangrove menjadi sirup, selai, permen, dodol dan sabun" termasuk kategori tidak terampil. Sebelum penyuluhan jumlah yang terampil $20 \%$, tidak terampil $80 \%$. Setelah penyuluhan jumlah yang terampil $75 \%$ yang belum terampil $25 \%$.

\section{Perubahan Tindakan}

Menurut Kamus Besar Bahasa Indonesia kata “tindakan” berarti perbuatan, atau sesuatu nyang dilakukan. Selain itu juga berarti tindakan yang dilakukan untuk mengatasi sesuatu. Menurut Notoatmodjo (2011), dilihat dari bentuk respons terhadap stimulus, maka perilaku dapat dibedakan menjadi dua. 1. Bentuk pasif /perilaku tertutup (covert behavior). Respons seseorang terhadap stimulus dalam bentuk terselubung atau tertutup. Respons atau reaksi terhadap stimulus ini masih terbatas pada perhatian, persepsi, pengetahuan atau kesadaran dan sikap yang terjadi pada seseorang yang menerima stimulus tersebut, dan belum dapat diamati secara jelas oleh orang lain. 2. Perilaku terbuka (overt behavior) Respons terhadap stimulus tersebut sudah jelas dalam bentuk tindakan atau praktik, yang dengan mudah dapat diamati atau dilihat orang lain. Menurut Notoatmodjo (2007) sikap belum tentu menghasilkan Tindakan. Untuk mewujudkan menjadi tindakan diperlkukan faktor pendukung misalnya fasilitas dan dukungan.

Perubahan tindakan dalam hal ini maksudnya kegiatan dalam mengolah buah mangrove. Untuk mengetahui perubahan tindakan dengan cara membandingkan jumlah orang yang pernah mengolah buah mangrove sebelum penyuluhan dengan jumlah orang yang mengolah buah mangrove setelah penyuluhan. Sebelum penyuluhan, jumlah responden yang pernah mengolah buah mangrove $60 \%$. Dari yang pernah mengolah $40 \%$ mengolah menjadi sirup, $20 \%$ menjadi dodol. Setelah penyuluhan $85 \%$ reeponden mengolah buah mangrove. Dari $85 \%$ yang mengolah tersebut, $75 \%$ mengolah menjadi sirup dan $10 \%$ mengolah menjadi dodol. Sebagian besar sudah bisa mengolah menjadi sirup dan dodol sejak sebelum diadakan penyuluhan. Akan tetapi setelah penyuluhan belum ada responden yang mencoba mengolah buah mangrove menjadi selai, permen dan sabun. Selain itu setelah penyuluhan masih terdapat $15 \%$ responden yang belum mencoba/melakukan pengolahan. Menurut penjelasan responden kondisi tersebut disebabkan karena kurang faham, kurang menguasai, merasa kurang percaya diri dan belum ada fasilitas.

Semua (100\%) responden menyatakan ingin mengembangkan usaha olahan buah mangrove. Menurut responden untuk mengembangkan usaha tersebut perlu bantuan modal, bantuan pemasaran, pembinaan kemampuan, pendampingan usaha, ' dukungan sumber daya manusia dan bantuan pemerintah. 


\section{KESIMPULAN}

Hasil pengabdian masyarakat : 1. Penyuluhan mengenai manfaat mangrove dan pengolahan buah mangrove jelas, mudah diterima oleh sasaran dan sangat berguna; 2 . Menghasilkan : sirup, selai, permen, dodol dan sabun buah mangrove, untuk diuji rasa, uji hygiene, analisis kelayakan finansial dan perlu dilakukan eksperimen untuk optimalisasi produk; 3. Terdapat peningkatan jumlah sasaran yang mengetahui, manfaat mangrove untuk lingkungan (20\%) dan ekonomi (70\%), olahan dan cara mengolah buah mangrove menjadi sirup (15\%), selai (100\%), permen $(95 \%)$, dodol $(25 \%)$ dan sabun $(100 \%)$; 4. Terdapat peningkatan jumlah sasaran (40\%) menjadi $100 \%$ ingin mengolah buah mangrove dengan alasan sebagai sumber pendapatan alternatif, memberi manfaat sumberdaya dan menambah/membuka lapangan kerja; 5.Terdapat peningkatan jumlah sasaran yang bisa mengolah buah mangrove $(50 \%)$; 6. Sebagian responden sudah pernah mengolah mangrove menjadi sirup dan dodol untuk konsumsi sendiri sebelum penyuluhan, dan bertambah jumlahnya (50\%) sesudah penjuluhan. Akan tetapi setelah penyuluhan masih ada yang belum mencoba mengolah (15\%) dan belum ada sasaran yang mengolah menjadi selai, permen dan sabun. Hal tersebut disebabkan karena kurang faham, kurang menguasai, merasa kurang percaya diri serta belum ada modal dan fasilitas.

Perlu dilakukan : 1. Uji coba/eksperimen pengolohan buah mangrove untuk mendapatkan produk yang berkualitas dan memenuhi selera konsumen ; 2. Uji rasa, uji hygiene, serta analisis kelayakan finansial usaha. 3. Pembinaan berkelanjutan, pendampingan, pemberian bantuan modal, bantuan pemasaran dan fasilitas dari stake holders untuk perintisan dan pengembangan usaha pengolahan buah mangrove.

\section{REFERENSI}

Griffin, Ricky W dan Ronald J. Ebert. 2003. "Business” edisi ke-6. Terjemahan Indonesia. Jakarta: Prenhalindo

Gordon. 1994. Pengertian Keterampilan, Macam, Contoh dan Menurut Para Ahli. https://pendidikan.co.id/pengertian-keterampilan-macam-contoh-dan-menurutpara-ahli/. Diposting oleh Parta Ibeng 4 Maret 2021. Diakses 25 April 2021 pukul 06.00 .

Kamus Besar Bahasa Indonesia

Kartasapoetra, A.G.. 1994. Teknologi Penyuluhan Pertanian. Jakarta : Bumi Aksara. Lilian Sarah Hiariey. 2009. Identifikasi Nilai Ekonomi Ekosistem Hutan Mangrove.

Jurnal Organisasi dan Manajemen, Volume 5, Nomor 1, Maret 2009, 23-34

Mardikanto, T. 1993. Penyuluhan Pembangunan Pertanian. Surakarta: Sebelas Maret University Press.

Notoatmodjo, S. 2007. Pendidikan dan Perilaku Kesehatan. Jakarta : Rineka Cipta.

Notoatmodjo, S. 2011. Kesehatan Masyarakat, Ilmu dan Seni. Jakarta: Rineka Cipta

Robbins, Stephen P. 2007. Perilaku Organisasi Buku 1. Jakarta : Salemba Empat.

Everett M. Rogers. 1983. Diffusion of Innovations. London: The Free Press

Soedarmanto. 1992. Dasar-dasar dan Pengelolaan Penyuluhan. Malang: Pertanian Universitas Brawijawa.

Stewart, Allen Mikcchell., 1994. Empowering People. London : Pustman Publishing,

Undang-Undang Republik Indonesia Nomor 6 Tahun 2014 Tentang Desa 